\title{
Atributos químicos de um latossolo vermelho com base nas doses de lodo de esgoto
}

\section{Chemical attributes of an Oxisol regarding sewage sludge rates}

\author{
Fabio Olivieri de Nobile ${ }^{1 *}$, Paloma Helena da Silva Libórioํㅜ Ivana Marino Bárbaro², \\ Renan Ramos Fioramonte ${ }^{3}$ \\ ${ }^{1}$ Centro Universitário da Fundação Educacional de Barretos (UNIFEB) - Barretos, SP, Brasil. \\ ${ }^{2}$ Agência Paulista de Tecnologia dos Agronegócios (APTA), Secretaria da Agricultura e Abastecimento - \\ São Paulo, SP, Brasil. \\ ${ }^{3}$ Ten West Cattle Inc., Elgin (NE) - Estados Unidos.
}

\section{Resumo}

O lodo de esgoto possui alguns nutrientes essenciais às plantas (nitrogênio, fósforo e micronutrientes), apresenta teores de umidade variável e é rico em matéria orgânica. Dessa forma, deve ser visto como um complemento à adubação das culturas, podendo reduzir a utilização de fertilizantes químicos e o custo da adubação, pois uma maior disponibilidade de nutrientes no solo decorrente da aplicação desse resíduo pode levar a um melhor desenvolvimento da planta e, consequentemente, ao aumento da produtividade. O presente experimento foi desenvolvido no Centro Universitário da Fundação Educacional de Barretos e utilizou o lodo da Estação de Tratamento de Esgoto de Olímpia (SP) para avaliar alterações nas propriedades químicas do solo. O delineamento experimental utilizado foi o de blocos ao acaso, contendo quatro repetições constituídas de cinco doses de lodo de esgoto $(0 \%, 50 \%, 100 \%, 150 \%$ e $200 \%)$, totalizando 20 unidades experimentais. Na dose de $200 \%$ de lodo de esgoto, observaram-se as maiores concentrações de $\mathrm{Ca}, \mathrm{Mg}$, $\mathrm{MO}, \mathrm{K}, \mathrm{Pe} \mathrm{SO}_{4}^{-2}$, para a dose de $100 \%$, os menores valores de $\mathrm{H}^{+} \mathrm{Al}$. O pH variou entre 5,16 e 6,18, sendo a menor concentração obtida na dose de $0 \%$ e o maior teor obtido nas doses de $100 \%$. Portanto, fica claro que o uso de lodo de esgoto em doses adequadas pode ser uma opção como fonte de nutrientes de plantas, minimizando problemas de descarte, por corresponder a requisitos ambientais e econômicos.

Palavras-chave: biossólido; disposição final; fertilidade do solo; reutilização de resíduos.

\begin{abstract}
Sewage sludge has some of the essential plant nutrients (nitrogen, phosphorus and micronutrients), features variable moisture content and is rich in organic matter. Therefore, it should be seen as a complement to crops fertilization and may contribute to reducing the use of chemical fertilizers and the cost of fertilizer, as the increased availability of nutrients in the resulting soil application of this waste, can lead to better development of plant and consequently an increase in productivity. This experiment was conducted in UNIFEB-Barretos and used the sludge from Sewage Treatment Plant at Olímpia-SP, in order to evaluate changes in soil properties. The experimental design was randomized blocks, with four replicates of five installments, four with the application of sewage sludge doses $(0,50,100,150$ and 200\%), totaling 20 experimental units. We found that at doses of $200 \%$ of sewage sludge in Rhodic were the ones that showed the highest increases $\mathrm{Ca}, \mathrm{Mg}, \mathrm{MO}$, $\mathrm{K}, \mathrm{P}_{\text {and }} \mathrm{SO}_{4}^{-2}$. Doses of $100 \%$ were represented in the lower content of $\mathrm{H}+\mathrm{Al}$. The $\mathrm{pH}$ varied between 5.16 and 6.18; It is the lowest level obtained in the doses $0 \%$ and the highest content achieved in the $100 \%$ dose. Therefore it is clear that the use of sewage sludge in appropriate doses may be an option as a supplier of plant nutrients and minimize disposal problems, because it corresponds environmental and economic requirements.
\end{abstract}

Keywords: sewage sludge; final disposal; soil fertility; reuse of waste.

\footnotetext{
*Autor para correspondência: Fabio Olivieri de Nobile - Centro Universitário da Fundação Educacional de Barretos (UNIFEB) - Av. Prof. Roberto Frade Monte, 3664 - Marieta - CEP: 14783-226 - Barretos (SP), Brasil - E-mail: fonobile@feb.br
}

Recebido em: 11 de julho de 2016

Aceito para publicação em: 10 de fevereiro de 2017 


\section{Introdução}

O lodo de esgoto é um material resultante dos processos de tratamentos primário e secundário do esgoto e altamente complexo quanto à composição. Esses tratamentos são necessários para adequar os efluentes aos padrões de lançamento impostos pela legislação vigente, removendo ou reduzindo as concentrações de substâncias presentes no esgoto que poderiam causar impacto ao ambiente. No entanto, em razão do grande volume, o destino do lodo produzido vem preocupando pesquisadores, órgãos ambientais, legisladores e empresas de tratamento do esgoto em todo o mundo (NOBILE et al., 2014).

Estudos realizados na Europa indicam uma projeção preocupante para os próximos anos, com o crescimento da produção de lodo de esgoto, principalmente porque muitos países em desenvolvimento terão aumentadas as capacidades de tratamento de esgotos (sanitário) (TERRA et al., 2015).

Pela composição rica em matéria orgânica, nitrogênio e fósforo $(P)$, tem se sugerido intensamente lodo de esgoto para ser aplicado na agricultura como condicionador e fertilizante do solo. Os benefícios que poderiam ser obtidos com sua aplicação se relacionam à reciclagem da matéria orgânica e ao aporte de nutrientes no solo, melhorando suas propriedades físicas, químicas $\mathrm{e}$ biológicas e a produtividade agrícola. Entretanto, como o lodo contém elevadas concentrações de contaminantes, essa prática pode resultar em adição direta de patógenos diversos e substâncias químicas não desejadas no solo agriculturável e, consequentemente, na cadeia alimentar. Outro fator preocupante é a composição variável do lodo nas diferentes regiões e épocas do ano, dificultando o monitoramento dos contaminantes (NOBILE et al., 2014).

De acordo com a Companhia Nacional de Abastecimento - CONAB (2015), atualmente os destinos dados ao lodo de esgotos, em diversos países, são aterros, incineração e aplicação na agricultura. Como a incineração é uma prática muito cara e ambientalmente indesejada, restam as outras opções de descarte.

Diversos trabalhos demonstram aumentos nos teores de cálcio $(\mathrm{Ca})$, magnésio $(\mathrm{Mg})$, fósforo $(\mathrm{P})$, potássio $(\mathrm{K})$, na matéria orgânica em solos tratados com lodo de esgoto. Em alguns casos, os aumentos são equiparáveis ou superiores aos obtidos com a adubação mineral recomendada para a cultura (GOMES et al., 2007).

Apesar disso, a complementação em micronutrientes é frequentemente apontada como imprescindível para obter boas produções (LOBO et al., 2013), uma vez que o resíduo é escasso nesse elemento.

A aplicação de lodo de esgoto pode resultar em incremento nos teores de matéria orgânica e na CTC (capacidade de troca de cátions) do solo (CHIBA et al., 2008). Por outro lado, as boas condições de degradação da matéria orgânica presentes em regiões tropicais, como no Brasil, tornam a presença de matéria orgânica no solo temporária e, por isso, em alguns trabalhos, não se verifica aumento de seus teores em razão da aplicação do resíduo (NASCIMENTO et al., 2014).

Caldeira Júnior et al. (2009) constataram o decréscimo do $\mathrm{pH}$ de solos tratados com lodo de esgoto, o qual foi atribuído à presença de substâncias ácidas no resíduo e ao processo de nitrificação. Por outro lado, o aumento do pH do solo em razão da aplicação do lodo de esgoto observado em alguns trabalhos (KIDD et al., 2007) resulta da alcalinidade dos materiais utilizados no processo de eliminação de patógenos e estabilização do lodo, como a cal virgem $(\mathrm{CaO})$ e a cal hidratada $\left[\mathrm{Ca}(\mathrm{OH})_{2}\right]$.

Neste contexto, Vieira et al. (2005) constataram que a aplicação de lodo de esgoto promoveu adequado aumento de P no solo, com influência positiva na produção do milho, contudo Simonete et al. (2003) não observaram alterações nos atributos químicos do solo e nenhuma resposta do milho quando o solo foi adubado com lodo de esgoto.

Diante disso, o presente trabalho teve o objetivo de avaliar os efeitos da adubação com lodo de esgoto em razão da substituição da adubação convencional nos parâmetros químicos do solo $\left(\mathrm{pH}, \mathrm{H}^{+} \mathrm{Al}, \mathrm{MO}, \mathrm{P}, \mathrm{K}, \mathrm{Ca}, \mathrm{Mg}\right)$.

\section{Material e Métodos}

O experimento foi conduzido em campo, no setor de horticultura do Centro Universitário da Fundação Educacional de Barretos, situada no município de Barretos (SP), com coordenadas geográficas de latitude 20 33 '26" Sul e longitude $48^{\circ} 34^{\prime} 04^{\prime \prime}$ 'Oeste, estando a uma altitude de 530 metros. O clima do município é predominantemente quente e seco. No verão, são registradas temperaturas médias que 
variam entre 30 e $38^{\circ} \mathrm{C}$; no inverno, a variação média cai dos 13 aos $20^{\circ} \mathrm{C}$.

O solo da área onde foi retirado o solo para execução do experimento corresponde ao Latossolo Vermelho distrófico (EMBRAPA, 2013). As análises foram realizadas no Laboratório de Solos da Fundação Educacional de Barretos (Unifeb). Na Tabela 1, constam as características químicas do solo.

O lodo de esgoto utilizado provém da Estação Compacta de Tratamento de Esgoto Córrego dos Pretos, localizada no município de Olímpia (SP), tendo sido utilizado lodo de descarte do reator anaeróbico de fluxo ascendente (UASB), o qual foi coletado diretamente de bags onde se encontrava previamente desaguado.

A caracterização dos macros e micronutrientes foi obtida de laudo realizado de acordo com a resolução Conama 357, pelo laboratório Controle Analítico Análises Técnicas Ltda., em Osasco (SP), contratado pela autarquia responsável pelo sistema de tratamento de esgoto do município. Os resultados estão descritos na Tabela 2.
O mesmo laboratório realizou análises segundo a norma ABNT-NBR 10.004 (ABNT, 2004)(Caracterização de resíduos sólidos), a fim de caracterizar o resíduo para obtenção de Cadri (cadastro de resíduos industriais), objetivando a deposição do passivo de lodo gerado na estação em aterro sanitário. Os dados da análise química do lodo estão descritos na Tabela 3.

O delineamento experimental utilizado foi o de blocos ao acaso, contendo quatro repetições, constituídas de cinco parcelas, sendo quatro com a aplicação de doses de lodo de esgoto $(50 \%, 100 \%$, $150 \%$ e $200 \%$ ) e uma parcela não contendo lodo algum $(0 \%)$, totalizando 20 unidades experimentais.

As doses de lodo de esgoto foram calculadas com base no valor de nitrogênio recomendado, tendo se adotado como referência a dose de nitrogênio igual a 680 g.m $\mathrm{m}^{2}$ (BRSEEDS, 2013). Portanto, as doses adotadas de lodo de esgoto foram de $\mathrm{D} 50 \%=0,12 \mathrm{~g}, \mathrm{D} 100 \%=0,24 \mathrm{~g}, \mathrm{D} 150 \%=0,48 \mathrm{~g}$, $\mathrm{D} 200 \%=0,72 \mathrm{~g}$. Todos os vasos receberam tratamento com calcário antes da incorporação do lodo de esgoto. A dosagem utilizada foi de $6,25 \mathrm{~g}$, que é proporcional a 2,5 $\mathrm{tha}^{-1}$.

Tabela 1. Informações da análise química do solo Latossolo Vermelho distrófico (pH, matéria orgânica [MO]), P, K, Ca, Mg, acidez potencial, soma de bases, capacidade de troca de cátions e saturação de bases.

\begin{tabular}{|c|c|c|c|c|c|c|c|c|c|}
\hline pH & M.O & $\mathbf{P}$ & $\mathbf{K}$ & Ca & Mg & $\mathbf{H}+\mathbf{A l}$ & SB & CTC & $\mathbf{V}$ \\
\hline $\begin{array}{c}\mathrm{CaCl}_{2} \\
\mathbf{0 , 0 1} \mathrm{M}\end{array}$ & $\mathrm{g} \mathrm{dm^{-3 }}$ & $\mathbf{m g ~ d m}^{-3}$ & 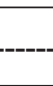 & 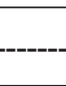 & $m$ & III & & & $\%$ \\
\hline 4,0 & 12,0 & 3,0 & 1,9 & 4,0 & 1,7 & 48,6 & 7,6 & 56,2 & 14,0 \\
\hline
\end{tabular}

Tabela 2. Composição química do lodo de esgoto classe I, base seca, da ETE de Olímpia (SP)ํ.

\begin{tabular}{ccc}
\hline Parâmetros determinados & Valores encontrados & Unidade \\
\hline Cor da amostra & Preto & - \\
Cianeto & $<1,00$ & $\mathrm{mg} / \mathrm{kg}$ \\
Fenol & 8,6 & $\mathrm{mg} / \mathrm{kg}$ \\
pH (solução 1:1) & 7,96 & - \\
Sulfeto & 341,95 & $\mathrm{mg} / \mathrm{kg}$ \\
Óleos e graxas & 7,14 & $\%$ \\
\hline
\end{tabular}

${ }^{1}$ Análise realizada no laboratório de análises químicas da Empresa Controle Analítico, Osasco (SP), 2012.

Tabela 3. Caracterizações químicas do lodo de esgoto conforme a especificação NBR 10.004 (ABNT, 2004).

\begin{tabular}{cccc}
\hline $\begin{array}{c}\text { Parâmetros } \\
\text { Determinados }\end{array}$ & Unidade & $\begin{array}{c}\text { Especificações } \\
\text { NBR 10.004 }\end{array}$ & Valores encontrados \\
\hline $\mathrm{pH}$ & - & - & 7,96 \\
$\mathrm{~N}$ & $\mathrm{~g} \mathrm{~kg}^{-1}$ & - & 79,1 \\
Cádmio $(\mathrm{Cd})$ & $\mathrm{mg} \mathrm{L}^{-1}$ & 0,005 & $<0,001$ \\
Chumbo $(\mathrm{Pb})$ & $\mathrm{mg} \mathrm{L}^{-1}$ & 0,01 & $<0,005$ \\
Manganês $(\mathrm{Mn})$ & $\mathrm{mg} \mathrm{L}^{-1}$ & 0,1 & 0,030 \\
Sulfatos $\left(\mathrm{SO}_{4}\right)$ & $\mathrm{mg} \mathrm{L}^{-1}$ & 250,0 & $<10,0$ \\
\hline
\end{tabular}


As doses foram misturadas ao solo, com a ajuda de sacos plásticos de 50 litros, e colocadas em vasos de polietileno com capacidade de 5 litros.

Para mensurar o potencial de vaporização d'água da atmosfera, utilizou-se um atmômetro da marca SEEI ${ }^{\circledR}$. Esse aparelho pode estimar a evapotranspiração (ET) de referência com boa precisão, cujas medidas de evaporação foram tomadas com base para definir as lâminas de água a serem aplicadas na irrigação. A irrigação foi realizada levando em consideração o solo na sua capacidade de campo, com reposição diária de $150 \%$ de ET, para que a água de irrigação escoe através do solo e se obtenha a água lixiviada para análise. A irrigação foi feita de maneira individual e a distribuição da água nas parcelas, em provetas graduadas com capacidade para 1 litro. O Kc (coeficiente da cultura) da grama Cynodon dactylon utilizado para calcular a quantidade de água a ser aplicada por vaso segue a metodologia sugerida por Hernandez (2006), em que Kc inicial foi de 0,4 , fase de desenvolvimento, $\mathrm{Kc}=0,7$, período intermediário, $\mathrm{Kc}=1,0$, final do ciclo, $\mathrm{Kc}=0,75$ e no período da colheita, $\mathrm{Kc}=0,5$.

O plantio das mudas Cynodon dactylon foi realizado colocando-se 10 estolões (com cerca de $10 \mathrm{~cm}$ de comprimento cada um) por vaso e, aos 34 dias do plantio, foi feito corte de uniformização a $10 \mathrm{~cm}$ da superfície do solo.

De acordo com Hernandez (2006), com as leituras diárias, não se obteve ET, portanto torna-se necessária a conversão da evaporação do atmômetro para evapotranspiração de referência (ETo). A ETo é definida como a perda de água de uma superfície coberta de vegetação rasteira, em fase de desenvolvimento ativo, cobrindo totalmente o aterro com umidade adequada ao desenvolvimento ótimo da planta. Essas condições observadas determinam que somente os parâmetros externos à superfície sejam os responsáveis pelo processo de ET.

No entanto, o que realmente se deseja é a ET da cultura, ou seja, deverá repor a água consumida pela cultura de interesse econômico e esse consumo varia em função do estágio de desenvolvimento da cultura e de cultura para cultura. Assim, a ET da cultura foi obtida multiplicando-se a ET de referência pelo coeficiente de cultura $(\mathrm{Kc})$ :

$\mathrm{ETc}=\mathrm{ETo} \times \mathrm{Kc}$

Onde $\mathrm{Kc}=\mathrm{f}$ (espécie, estádio).
Decorridos 90 dias da fertilização com lodo de esgoto, foram coletadas seis amostras simples, em pontos ao acaso, por vaso. As amostras foram secas ao ar por três dias, peneiradas em peneira com malha de \# $2 \mathrm{~mm}$ e uma parte das amostras, de 250 a $300 \mathrm{dm}^{3}$, foi encaminhada ao Laboratório de Fertilidade do Solo e Nutrição de Plantas (Fertplan) para quantificar os parâmetros químicos.

Nas amostras, foram determinados o $\mathrm{pH}\left(\mathrm{CaCl}_{2}\right.$ 0,01 mol.L-1), a matéria orgânica (Walkley-Black), $\mathrm{P}$ (resina), $\mathrm{K}$ (resina), $\mathrm{Ca}$ (resina), $\mathrm{Mg}$ (resina), $\mathrm{H}^{+} \mathrm{Al}\left[\mathrm{Ca}(\mathrm{OAc})_{2}\right.$ 0,5 mol. L-1] e com base nos resultados serão calculadas a soma de base (SB), a capacidade de troca de cátions (CTC) e a saturação por bases (V\%), empregando-se a metodologia descrita por Van Raij et al. (2001).

Para avaliar o efeito das doses de lodo de esgoto sobre os parâmetros químicos do solo, utilizou-se a análise de regressão polinomial, sendo considerada a melhor dose a que apresentou o melhor ajuste, ou seja, apresentou o maior $\mathrm{R}^{2}$. Utilizaram-se os procedimentos do statistical analysis system (SAS Institute, 1999).

\section{Resultados e Discussão}

De acordo com a Figura 1, observa-se a quantidade de matéria orgânica no solo submetido à aplicação de diferentes doses de lodo de esgoto.

A matéria orgânica do solo em decomposição, sob a influência do clima e do meio ambiente, libera gás carbônico e compostos orgânicos. O solo é o maior reservatório de carbono e representa um grande papel na estocagem dessa substância no solo (sequestro), minimizando a liberação de gases para a atmosfera (NOBILE et al., 2014)

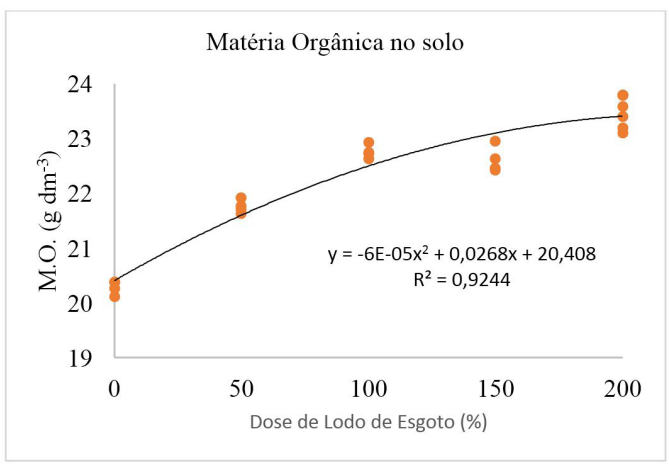

Figura 1. Curva de avaliação dos valores de matéria orgânica encontrada no Latossolo Vermelho de acordo com as doses de esgoto aplicadas. 
Verificou-se, ainda, que a maior quantidade de matéria orgânica ocorreu com a aplicação de $200 \%$ de lodo de esgoto. Inicialmente, a quantidade de matéria orgânica foi baixa, seguida de uma elevação nas doses de $50 \%$ e $100 \%$ e uma baixa nas doses de $150 \%$, até chegar à sua maior taxa nas doses de $200 \%$.

A quantidade de material orgânico adicionado nos tratamentos acarreta benefícios às condições químicas do solo. A influência da MOS na agregação do solo é um processo dinâmico, sendo necessário acréscimo contínuo de material orgânico para manter a estrutura adequada e a distribuição do espaço poroso do solo, característica afetada pela matéria orgânica (WOHLENBERG et al., 2004).

A Figura 2 apresenta a taxa de $\mathrm{pH}$ e $\mathrm{H}^{+} \mathrm{Al}$ em função dos diferentes tratamentos. A máxima taxa de $\mathrm{H}^{+} \mathrm{AL}$ foi obtida nas amostras em que não houve aplicação de lodo de esgoto ( $0 \%$ ), seguida de uma baixa nas doses de $50 \%$ e $100 \%$ e uma elevação nas doses de $150 \%$ e $200 \%$, respectivamente.

A faixa ideal de $\mathrm{pH}$ para o desenvolvimento das plantas é de 6,0 a 6,5. Os solos ácidos apresentam problemas para a agricultura porque as plantas não se desenvolvem bem nessas condições de acidez. A disponibilidade de nutrientes é muito pequena para as plantas (NOBILE et al., 2014).

$\mathrm{O}$ teor de $\mathrm{H}^{+} \mathrm{Al}$ diminuiu com o aumento da dose do composto, enquanto o $\mathrm{pH}$, como era esperado, não se alterou. É provável que os maiores valores de $\mathrm{H}^{+} \mathrm{Al}$ se devam ao caráter acidificante do lodo de esgoto utilizado como fonte de nutriente. A não elevação do valor de $\mathrm{pH}$ do solo está de acordo com as observações de diversos autores de que, de maneira geral, a aplicação de composto umificado ao solo não promove elevação de seu pH (COKER e MATTHEWS, 1983). Um fator importante que pode ter colaborado para diminuir a acidez potencial é a possível formação de complexos estáveis entre o Al trocável e a matéria orgânica aplicada (BONINI et al., 2015).

$\mathrm{Na}$ Figura 3, pode-se observar que as maiores quantidades de potássio foram encontradas nas amostras onde foram aplicadas doses de $200 \%$ de lodo de esgoto.

As concentrações de potássio sofreram aumentos significativos em função das doses de lodo de esgoto, provavelmente devidos à mineralização de parte desses elementos que estavam na forma orgânica.
O potássio (K) é absorvido pelas plantas na forma de íon $\mathrm{K}^{+}$. As plantas absorvem o potássio da solução do solo, cuja concentração é mantida pelo equilíbrio com o potássio retido nos sítios de troca (trocável). Entretanto, quando a concentração de $\mathrm{K}$ na solução atinge valores muito baixos, pode haver difusão de parte do potássio contido nas estruturas dos argilominerais e dissolução dos minerais primários que contêm $\mathrm{K}$, indicando que as formas de $\mathrm{K}$ não trocáveis se encontram potencialmente disponíveis para as plantas.

Resultados semelhantes foram constatados por Garcia et al. (2009), que aplicaram doses de lodo de esgoto de $0,25,50,75$ e 100 t.ha ${ }^{-1}$ de lodo de esgoto e verificaram aumento crescente de potássio no solo para cada incremento de dose.

Frequentemente, a complementação potássica é imprescindível para obter boas produções, uma vez que o lodo de esgoto é deficiente em potássio

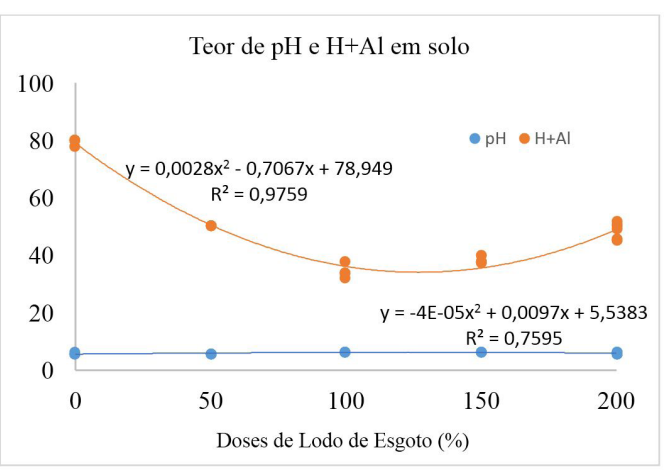

Figura 2. Curva dos valores de $\mathrm{pH}$ e $\mathrm{H}^{+} \mathrm{Al}$ de acordo com as doses de lodo de esgoto de $50 \%$, $100 \%, 150 \%, 200 \%$ e $0 \%$ (nenhuma adubação).

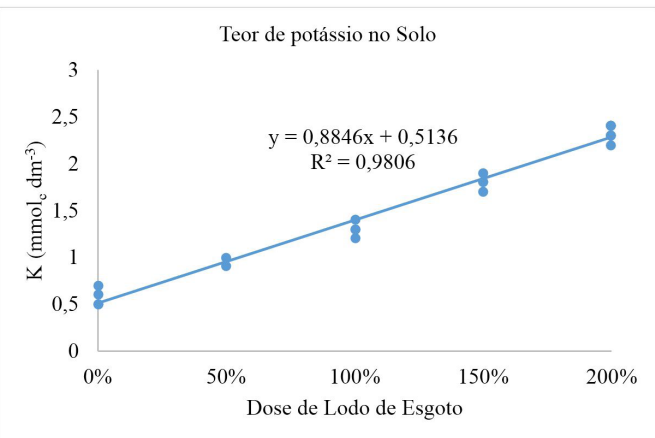

Figura 3. Curva dos valores de potássio no solo de acordo com as doses de lodo de esgoto de $50 \%$, $100 \%, 150 \%, 200 \%$ e $0 \%$ (nenhuma adubação). 
por causa da alta solubilidade desse elemento em água (SILVA et al., 2010).

$\mathrm{Na}$ Figura 4, observa-se um crescimento da taxa de P de acordo com o aumento das dosagens de lodo, sendo a maior taxa encontrada nas amostras com doses de $200 \%$ de lodo de esgoto.

Para o teor de $\mathrm{P}$, o efeito foi significativo entre as doses, tendo o maior valor de $\mathrm{P}$ sido verificado na dose de $200 \%$ da recomendação de $\mathrm{P}$ para a cultura, corroborando os resultados encontrados por Costa et al. (2014) que verificaram aumento considerável do teor de P no solo com o uso de lodo de esgoto, o qual foi incorporado ao solo manualmente e até a camada $0,10 \mathrm{~m}$, com o auxílio de enxada, de 2001 a 2006, entre 5 e 10 dias antes da semeadura do milho.

$\mathrm{O}$ aumento significativo estatisticamente de $\mathrm{P}$ no solo pode ser explicado pela disponibilização desse elemento, uma vez que com a dose de $200 \%$ foram adicionados $40 \mathrm{mg} \cdot \mathrm{dm}^{-3} \cdot \mathrm{kg}$ de P. Bonini et al. (2015) analisaram atributos químicos em área degradada em recuperação, com lodo de esgoto, e verificaram que houve incremento no teor de $\mathrm{P}$ de $70 \%$ e $50 \%$ nas camadas superficial e subsuperficial, respectivamente.

Segundo Ayuso et al. (1992), o lodo de esgoto é composto de boa fonte de $\mathrm{P}$, derivado na maioria das partes de detergente (polifosfatos), e a aplicação de lodo de esgoto aos solos eleva a quantidade de P disponível e, consequentemente, a absorção desse elemento pelas plantas.

$\mathrm{P}$ é absorvido pelas plantas sob a forma de ânions $\mathrm{H}_{2} \mathrm{PO}_{4}^{-}$em solos ácidos e $\mathrm{HPO}_{4}^{2-}$, sendo um nutriente altamente dependente de acidez e umidade do solo (MURAISHI et al., 2011).

Conforme dados da Figura 5, o aumento nas doses de composto de lodo de esgoto resultou em incremento nos teores de Ca no solo. Tal fato reflete os teores existentes no composto de lodo utilizado, que foi da ordem de 4,0 g. $\mathrm{kg}^{-1}$ de Ca.

Observa-se que houve variação na taxa de $\mathrm{Ca}$ de acordo com os tratamentos, crescimento até as doses de $100 \%$ de lodo, logo após decréscimo de Ca nas doses de $150 \%$ e, novamente, um aumento atingindo o valor máximo nas doses de $200 \%$.

Segundo Giracca et al. (2016), os efeitos indiretos de Ca são tão importantes quanto seu papel como nutriente. Ca reduz a acidez do solo, melhora o crescimento das raízes, o aumento da atividade microbiana, da disponibilidade de molibdênio (Mo) e de outros nutrientes. Ao reduzir a acidez do solo, diminui a toxidez do alumínio

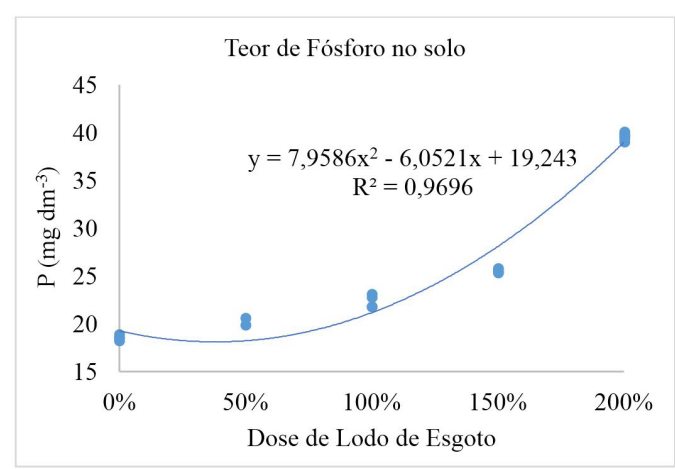

Figura 4. Curva dos valores de $\mathrm{P}$ encontrada no solo de acordo com as doses de lodo esgoto de $50 \%$, $100 \%, 150 \%, 200 \%$ e $0 \%$ (nenhuma adubação).

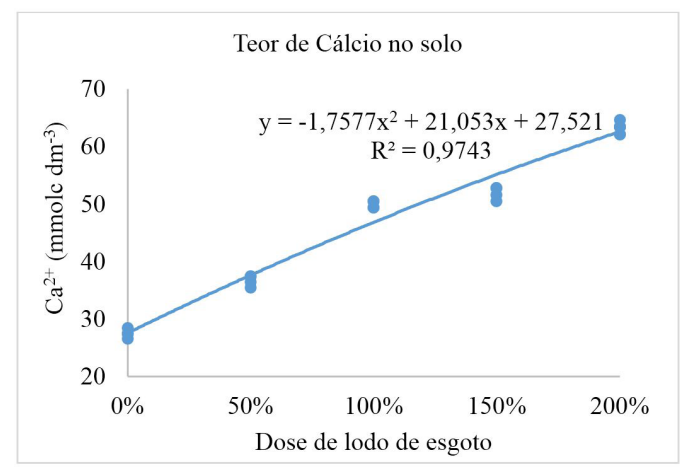

Figura 5. Curva dos valores de Ca de acordo com as doses de lodo de esgoto de $50 \%, 100 \%, 150 \%$, $200 \%$ e $0 \%$ (nenhuma adubação).

(Al), cobre $(\mathrm{Cu})$ e manganês $(\mathrm{Mn})$. Plantas que apresentam altos teores de Ca resistem melhor à toxidez desses elementos.

A Figura 6 apresenta a taxa de $\mathrm{Mg}$ segundo os diferentes tratamentos. No entanto, os teores de $\mathrm{Mg}$ no solo, em razão de sua menor concentração no composto de lodo, não foram influenciados pela aplicação desse resíduo, e as quantidades de $\mathrm{Mg}$ presente no lodo não são suficientes para suprir as necessidades da maioria das culturas, mesmo quando aplicado em altas doses. A diminuição de $\mathrm{Mg}$ em razão da aplicação de lodo de esgoto foi também confirmada por Antolin et al. (2005) e Chueiri et al. (2007).

A diminuição dos teores de $\mathrm{Mg}$ no solo em razão do efeito de doses crescentes de lodo de esgoto também foi constatada por Barbosa et al. (2007), que verificaram que a baixa concentração no solo se deve aos baixos níveis do elemento no resíduo e à alta absorção do elemento pela planta. 


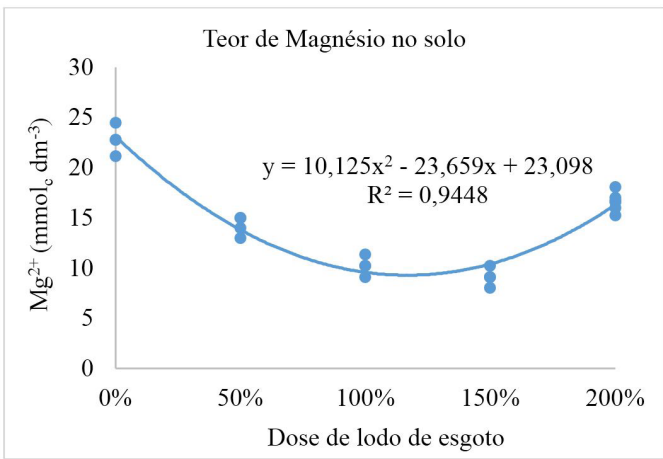

Figura 6. Curva dos valores de $\mathrm{Mg}$ de acordo com as doses de lodo de esgoto de $50 \%, 100 \%$, $150 \%, 200 \%$ e $0 \%$ (nenhuma adubação).

\section{Conclusão}

Doses de $200 \%$ de lodo de esgoto em Latossolo Vermelho foram as que apresentaram os maiores aumentos de $\mathrm{Ca}, \mathrm{Mg}, \mathrm{MO}, \mathrm{K}$ e $\mathrm{P}$.

Doses de 100\% apresentaram os menores teores de $\mathrm{H}^{+} \mathrm{Al}$. O pH variou entre 5,16 e 6,18, tendo o menor valor sido obtido nas amostras em que se aplicou apenas calcário e a maior taxa sido obtida nas amostras com doses de $100 \%$ de lodo de esgoto.

Portanto, fica claro que o uso de lodo de esgoto em doses adequadas pode ser uma opção como fonte de nutrientes de plantas, minimizando problemas de descarte, por corresponder a requisitos ambientais e econômicos.

\section{Referências}

ANTOLIN, M.C.; PASCUAL, I.; GARCIA, C.; POLO, A.; SANCHEZ-DIAZ, M. Growth, yield and solute content of barley in soils treated with sewage sludge under semiarid Mediterranean conditions. Field Crops Research, v. 94, p. 224$237,2005$.

\section{ASSOCIAÇÃO BRASILEIRA DE NORMAS} TÉCNICAS - ABNT. NBR 10004: 2004 : resíduos sólidos - classificação. Rio de Janeiro, 2004. p. 71.

AYUSO, M.; HERNÁNDEZ, T.; GARCIA, C.; COSTA, F. Utilización de un lodo aerobio como substitutivo de fertilizantes fosforados inorgánicos. Suelo y Planta, v. 2, n. 2, p. 271-280, 1992.
BARBOSA, G.M. C.; TAVARES FILHO, J.; BRITO, O.B.; FONSECA, I.C.B. Efeito residual do lodo de esgoto na produtividade do milho safrinha. Revista Brasileira de Ciencia do Solo, v. 31, p. 601-605, 2007.

BONINI, C.B.; ALVES, M.C.; MONTANARI, R. Lodo de esgoto e adubação mineral na recuperação de atributos químicos de solo degradado. Revista Brasileira de Engenharia Agrícola e Ambiental, v. 19, n. 4, p. 388-393, 2015.

BRSEEDS. Como formar seu gramado. 2013. p. 7. Disponível em: <http: http://ww2.brseeds.com/ grama/Forma\%C3\%A7\%C3\%A3o_de_Gramados. pdf $>$ Acesso em: 30 jun. 2015.

CALDEIRA JÚNIOR, C.F.; SOUZA, R.A.; SANTOS, A.M.; SAMPAIO, R.S.; MARTINS, E.R. Características químicas do solo e crescimento de Astronium fraxinifolium Schott em área degradada adubada com lodo de esgoto e silicato de cálcio. Revista Ceres, v. 56, n. 1, p. 213-218, 2009.

CHIBA, M.K.; MATTIAZZO, M.E.; OLIVEIRA, F.C. Cultivo de cana-de-açúcar em Argissolo tratado como lodo de esgoto. I: Disponibilidade de nitrogênio no solo e componentes de produção. Revista Brasileira de Ciencia do Solo, v. 32, n. 2, p. 643-532, 2008

CHUEIRI, W.A.; SERRA, T.B.M.; BIELE, J.; FAVARETTO, N. Lodo de esgoto e fertilizante mineral sobre parâmetros do solo e de plantas de trigo. Revista Brasileira de Engenharia Agrícola e Ambiental, v. 11, p. 502-508, 2007.

COKER, E.G.; MATTHEWS, P.J. Metals in sewage sludge and their potential effects in agriculture. Water Science and Technology, v. 15, p. 209-225, 1983.

COMPANHIA NACIONAL DEABASTECIMENTO - CONAB. Relatório de Insumos Agropecuários 2015. Disponível em: <http://consultaweb. conab.gov.br/consultas/consultaInsumo. do? method=acaoListarConsulta $>$. Acesso em: 12 mar. 2015.

COSTA, V.L.; MARIA, I.C.; CAMARGO, O.A.; GREGO, C.R.; MELO, L.C.A. Distribuição espacial de fósforo em Latossolo tratado com lodo de esgoto e adubação mineral. Revista Brasileira 
de Engenharia Agrícola e Ambiental, v. 18, p. 287-293, 2014.

EMPRESA BRASILEIRA DE PESQUISA AGROPECUÁRIA - EMBRAPA. Sistema brasileiro de classificação de solos. 3. ed. Brasília, 2013. 353 p.

GARCIA, G.O.; GONÇALVES, I.Z.; MADALÃO, J.C.; NAZÁRIO, A.A.; REIS, E.F. Análise nutricional de mudas de eucalipto submetidas à aplicação de lodo de esgoto doméstico. Revista Engenharia Ambiental, v. 6, n. 3, p. 275-290, 2009.

GIRACCA, E.M.N.; NUNES, J.L.S. AGROLINK: fertilizantes e corretivos. Nitrogênio, fósforo, potássio magnésio, enxofre. Disponível em: $<$ http:// www.agrolink.com.br/ fertilizantes/Nutrientes. aspx>. Acesso em: 10 jun. 2016.

GOMES, S.B.V.; NASCIMENTO, C.W.A.; BIONDI, C.M. Produtividade e composição mineral de plantas de milho em solos adubado com lodo de esgoto. Revista Brasileira de Engenharia Agrícola e Ambiental, v. 11, p. 459-465, 2007.

HERNANDEZ, F.B.T. Manejo da Irrigação. abr 2006. Disponível em: $<$ http://www.agr.feis.unesp. br/curso3.htm>. Acesso em: 30 jun. 2015.

KIDD, P.S.; DOMÍNGUEZ-RODRÍGUEZ, M.J.; DÍEZ, J.; MONTERROSO, C. Bioavailability and plant accumulation of heavy metals and phosphorus in agricultural soils amended by longterm application of sewage sludge. Chemosphere, v. 66, n. 8, p. 1458-1467, 2007.

LOBO, T.F.; GRASSI FILHO, H.; BULL, L.T.; KUMMER, A.C.B. Efeito do lodo de esgoto e do nitrogênio nos fatores produtivos do girassol. Revista Brasileira de Engenharia Agrícola e Ambiental, v. 17, n. 5, p. 504-509, 2013.

MURAISHI, C.T.; ALVES, M.C.; SILVA JÚNIOR, A.; SOUZA, Z.M. Chemical attributes of a savannah Typic Hapludox soil under management systems. Acta Scientiarum. Agronomy, v. 33, p. 551-557, 2011.

NASCIMENTO, A.L.; SAMPAIO, R.A.; ZUBA JUNIO, G.R.; FERNANDES, L.A.; CRUZ, S.F.;
CARNEIRO, J.P.; BARBOSA, C.F.; LIMA, N.N. Atributos químicos do solo adubado com lodo de esgoto estabilizado por diferentes processos e cultivado com girassol. Bioscience Journal, v. 30, n. 1, p. 146-153, 2014.

NOBILE, F.O.; NUNES, H.D.; NEVES, J.C. Doses de lodo de esgoto sobre o desenvolvimento da grama bermuda (Cynodon dactylon). Nucleus, v. 11, n. 2, p. 7-18, 2014.

VAN RAIJ, B.; ANDRADE, J.C.; CANTARELLA, H.; QUAGGIO, J.A. Análise química para avaliação da fertilidade de solos tropicais. Campinas: Instituto Agronômico, 2001. 285 p.

SAS INSTITUTE. SAS user's guide. Cary, 1999. $595 \mathrm{p}$.

SILVA, F.C.; BOARETTO, A.E.; ABREU JUNIOR, C.H.; BERTON, R.S.; BASSO, L.S.; BARBIERI, V. Impactos da aplicação de lodo de esgoto na cultura da cana-de-açúcar e no ambiente. HOLOS Environment, v. 10, n. 1, p. 62-82, 2010.

SIMONETE, M.A.; KIEHL, J.C.; ANDRADE, C.A.; TEIXEIRA, C.F.A. Efeito do lodo de esgoto em um Argissolo e no crescimento e nutrição de milho. Pesquisa Agropecuaria Brasileira, v. 38, p. 1187-1195, 2003.

TERRA, M.R.; SILVA, L.B.; IMBIRANI, J.R.; SILVEIRA, B.A.; FURLANETO, M.C.; MAIA, L.F. Resíduos de lodo de esgoto: avaliação de risco potencial ambiental e para a Saúde. In: V SIMPÓSIO DE BIOQUÍMICA E BIOTECNOLOGIA. Londrina, PR: Universidade Estadual do Paraná, 2015.

VIEIRA, R.F.; TANAKA, R.T.; TSAI, S.M.; PÉREZ, D.V.; SILVA, C.M.M.S. Disponibilidade de nutrientes no solo, qualidade de grãos e produtividade da soja em solo adubado com lodo de esgoto. Pesquisa Agropecuaria Brasileira, v. 40, p. 919-926, 2005.

WOHLENBERG, E.V.; REICHERT, J.M.; REINERT, D.J.; BLUME, E. Aggregation dynamics of a sandy soil under five cropping systems in rotation and in succession. Revista Brasileira de Ciencia do Solo, v. 28, p. 891-900, 2004. 